BIOINTERFACE RESEARCH IN APPLIED CHIEMISTRY

Volume 1, Issue 3, 2011, 089-094

Received: 15.05.2011 / Accepted: 1.06.2011 / Published on-line: 15.06.2011

\title{
Dynamics of innate immunity cytokines in patients with COPD
}

\section{Pasarica Daniela $^{1 *}$, Mihaela Gheorghiu ${ }^{1}$, Florica Toparceanu ${ }^{2}$, Loretta Ichim ${ }^{2}$, Coralia Belotu $^{2}$}

\section{ABSTRACT}

Chronic obstructive pulmonary disease (COPD) typically induces and maintains the activation of several phylogenetically old adaptative and defensive mechanisms. Activation is usually needed for a limited period during acute injury. In chronic disease conditions, however, those mechanisms are kept activated for longer periods. Eventually, irreversible damage is produced and this contributes to impaired function and worse prognosis in a variety of chronic diseases. The inflammatory cells and human bronchial smooth muscles are known to play an important role in the production of innate immunity cytokines and neurotrophins which have been recognized as mediators of both inflammatory and airway remodeling processes. When neurotrophins such as Neurotrophin 3 (NT-3) were initially discovered, they were thought to be only regulatory factors of the development, differentiation and survival of the neurons. Later, it was proved that they are also involved in inflammatory responses. In experimental animal models, neurotrophin may contribute to the development of bronchial hyperresponsivness. The persistent activation of the innate immune system by smoke exposure, releases the ROS that lead to a pronounced chronic inflammation of both airway and pulmonary parenchyma.

Keywords: $C O P D$, Neurotrophin 3, innate immunity, cytokines

\section{Introduction}

COPD is a major cause of morbidity and mortality worldwide. The major cause of COPD is smoking. Chronic lung diseases are caused by an unusual innate immune response because it is a repetitive response in which, an acute disease becomes a subacute and, later chronic [1]. The danger signals are represented by the reactive oxygen species and many other substances present in cigarette smoke that induce a persistent activation of the innate immune system leading to a pronounced and chronic inflammation in the airways and in the lung and to other pathological changes including the remodelling and destruction of lung tissue [2-8]. Toxic substances from smokers with COPD share many clinical and histologic features with other lung diseases attributed to bacterial lipopolysaccharide (LPS) inhalation [3-9]. Experimental LPS inhalation mimics many of the acute effects of the presence of cigarette smoke in the lower airways. Therefore, because cigarette smoke has been shown to contain bioactive endotoxins it may contribute to the airways inflammation in COPD [4-10]. The initiating factors, interacting with bronchial epithelial cells, alveolar macrophages human bronchial smooth muscle cells and NKT induce the release of chemotactic factors for

\footnotetext{
1 “Carol Davila” University Of Medicine AND Pharmacy, Bucharest, Romania

* Corresponding author e-mail address: pasaricadaniela@yahoo.com

2 "Stefan S. Nicolau" Institute Of Virology, Bucharest, Romania
} 
neutrophils, which, in turn, are important effector cells involved in inflammation and tissue damage by releasing neutrophil elastase (a potent matrix-degrading protein) and cytokines [5-11]. In the respiratory epithelium and macrophages the toll-like receptors (TLRs) are a key component of host defense [6-12] because they react on the danger signals represented by reactive oxygen intermediates [7-13]. Airway smooth muscle cells express TLR1 to TLR10, mRNA (and TLR2, TLR3, TLR4 protein expression was demonstrated) $[14,8]$. In the distal airways of a current smoker there was an increased expression of TLR4 while in former smokers there was a reduced expression of TLR2 [15]. Neutrophils also express TLRs 1, 2, 4, 5, 6, 7, 8, 9, and 10.TLR9 signalls to the neutrophils the production of CXC chemokine ligand (CXCL) 8 and this contribute to the accumulation of neutrophils and inflammation within the airways of smokers [16-9]. TLR stimulation on neutrophils can result in the shedding of L-selectin, increased phagocytosis, superoxide generation, and the production of a number of cytokines and chemokines [17, 10]. The activated macrophages localized in the lung tissue of patients with COPD, increase the level of IL-13 mRNA and recruit NKT cells were also more numerous in the lungs of COPD patients than in the lungs of healthy people [18-11]. Following activation, NKT cells can immediately start cytokine secretion without first having to differentiate into effector cells. The rapidity of their response makes NKT cells an important component of the long-term innate response. NKT cells recruit macrophages and stimulate the production of pro-inflammatory cytokines and additional macrophage activation [19]. The transduction of the signal through TLR and the adaptor molecules, the phosphorilation cascade and release of active AP-1, NFkB or IP3 activate nuclear promoter genes for the secretion of neutrophil chemokines and pro-inflammatory cytokines tumor necrosis factor $\alpha$ (TNF- $\alpha$ ) and interleukin-6, IL-1 and matrix metalloproteinases (MMPs) [20]. The cytokines TNF $\alpha$, IL-1 $\beta$ and IL-6 are critical mediators in the host responses to microbial pathogens, but also endogenous alarm signals, like apoptosis related membrane fragments and inflammatory ligands. These molecules can also induce host tissue injury [21]. Their harmful potential depends on the combination in which they are expressed. Prolongation of cytokine expression increases the likelihood of exposure to a potentially lethal citokine combination [22].

Transcription of these cytokines is activated by the pro-inflammatory transcriptional activator NFkB. Systemic inflammation induced by IL-6 production is now recognized as a component of COPD (23). A potentially relevant, pathogenic mechanism in chronic obstructive pulmonary disease is represented by gamma delta $\mathrm{T}$ cells, a small percentage of the total T-cell population, with a key role in tissue repair and mucosal homeostasis. Determined by flow cytometry in peripheral blood and bronchoalveolar lavage samples, obtained from patients with COPD, gamma delta T-lymphocytes were blunted in these patients [24]. Human bronchial smooth muscle cells may contribute to the airway remodeling via secretion of growth factors like neurotrophins such NT-3. In experimental animal models, NT-3 has been shown to be produced by glial cells as an adaptability response to hypoxia [25].

However recently it has been implicated also in inflammatory responses: NT-3 have been detected in blood and in the inflammation of the airways but the release of NT-3 can be downregulated after cigarette-smoke exposure. COPD patients, as well as smokers with normal lung function, showed decreased levels of NT-3 in the airways as compared to healthy non-smokers [26]. In the present work we investigated the presence and dynamics of innate immunity cytokines IL-1 $\beta$, TNF- $\alpha$ and IL-6 in serum of patients with COPD to find out if the expression of inflammatory cytokines may be differently regulated by NT-3. 


\section{Experimental section}

2.1. Patiens and Methods. 20 patients ( 4 female and 16 male) with COPD (mean age $61.0 \pm 14.19$ years; range 17 to 77 years; mean smoking history, $28.4 \pm 25.9$ pack-years) were recruited to the study (Table 1). The diagnosis of COPD was established by the clinical data and was confirmed by laboratory tests. Familial COPD as genetic factor and cigarette smoke were considered also as risk factors. The patients were stratified according to spirometry that confirms the presence of airflow obstruction and appreciates the severity of disease and GOLD (Global Initiative for Chronic Obstructive Lung Disease) staging system for COPD (Table 1).

Table 1: Staging of disease severity of COPD patients

\begin{tabular}{ccccc}
\hline $\begin{array}{c}\text { FEV/FVC } \\
\text { Ratio }\end{array}$ & $\begin{array}{c}\mathrm{FEV}_{1} \text { percent } \\
\text { predicted }\end{array}$ & $\begin{array}{c}\text { Stage } \\
\text { GOLD }\end{array}$ & Clinical course & $\begin{array}{c}\text { Patients } \\
\text { recruited to the } \\
\text { study }\end{array}$ \\
\hline $70 \%$ & $>80 \%$ & I & Mild & - \\
\hline $70 \%$ & $50-80 \%$ & II & With or without chronic symptoms & 9 \\
\hline $70 \%$ & $30-50 \%$ & III & With or without chronic symptoms & 7 \\
\hline $70 \%$ & $\begin{array}{c}<30 \% \text { or } \\
<50 \%\end{array}$ & IV & With chronic respiratory failure & 4 \\
\hline
\end{tabular}

$\mathrm{FEV}_{1}$, forced expiratory volume in 1 second; FVC, forced vital capacity; GOLD, Global Initiative for Chronic Obstructive Lung Disease.

Serum samples, obtained from venous puncture, were analyzed for IL- $1 \beta$, TNF- $\alpha$, IL- 6 and NT-3, using Coulter and EuroClone ELISA kits, according to manufacturer indications.

2.2. Dynamics of innate immunity cytokines in patients with COPD. Statistical analysis. For the analysis of correlations, the Pearson's correlation coefficient $r$ was used. The minimum threshold value accepted to consider a correlation as statisticaly significant was $p \leq 0.05$.

\section{Results section}

According to the clinical evolution and based on their IL-1 $\beta$, TNF $\alpha$ IL-6 and NT-3 serum level, the patients were dividing in three groups (Table 2).

Table 2: Characteristics of the groups of patients with COPD

\begin{tabular}{cccccc}
\hline Group & Clinical cours & IL-1 $\beta(\mathrm{pg} / \mathrm{ml})$ & TNF $\alpha(\mathrm{pg} / \mathrm{ml})$ & IL-6 $(\mathrm{pg} / \mathrm{ml})$ & NT-3 $(\mathrm{pg} / \mathrm{ml})$ \\
\hline \multirow{2}{*}{ A } & $\begin{array}{c}\text { Moderate COPD stage II } \\
\text { GOLD }\end{array}$ & $6.077 \pm 1.07$ & $22.384 \pm 8.73$ & $10.05 \pm 3.764$ & $364 \pm 120.89$ \\
\hline B & Severe COPD stage III & $8.662 \pm 3.408$ & $24.545 \pm 17,60$ & $15.084 \pm 7.28$ & $33.73 \pm 15.06$ \\
\hline C & Very severe stage IV GOLD & $9.606 \pm 4.953$ & $33.992 \pm 16.80$ & $19.05 \pm 3.764$ & $44.16 \pm 16.12$ \\
\hline & normal & $0.17 \pm 0.06$ & $3,1 \pm 0.53$ & $1.71 \pm 0.53$ & $5.52 \pm 2.54$ \\
\hline
\end{tabular}

NT-3 was direct correlated with IL-1 $\beta(r=0.83 p=0.05)$ Fig. 1 , TNF $\alpha(r=0.93 p=0.05)$ Fig. 2 and IL-6 $(\mathrm{r}=0.94 \mathrm{p}=0.05)$ Fig. 3 in patients with COPD moderate stage II GOLD. There are no correlations between these parameters in patients with severe and very severe GOLD stage III, IV GOLD. with greater degrees of obstruction of the airway. 


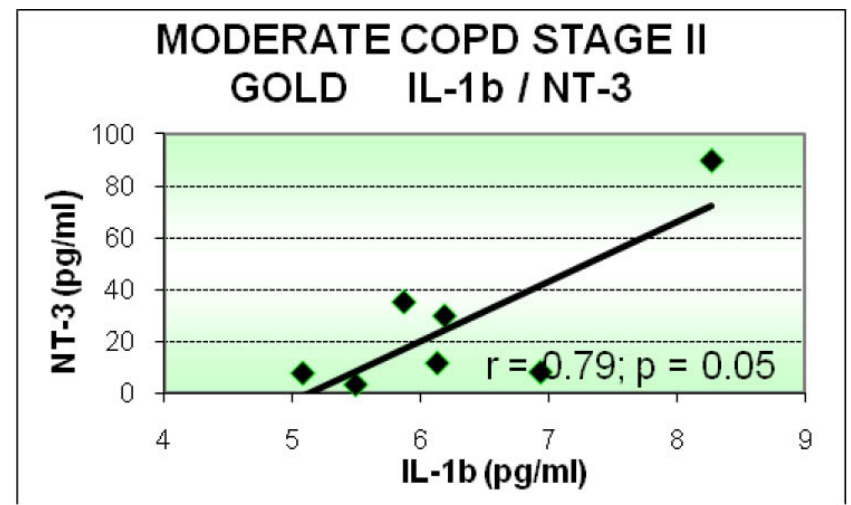

Figure 1: Correlation between serum level of NT-3 and IL-1 $\beta$ in patients with moderate COPD stage II GOLD

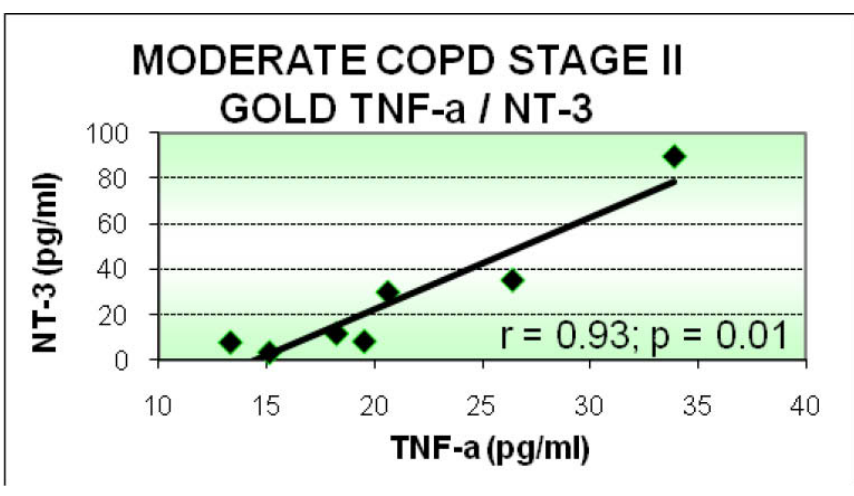

Figure 2: Correlation between serum level of NT-3 and TNF $\alpha$ in patients with moderate COPD stage II GOLD

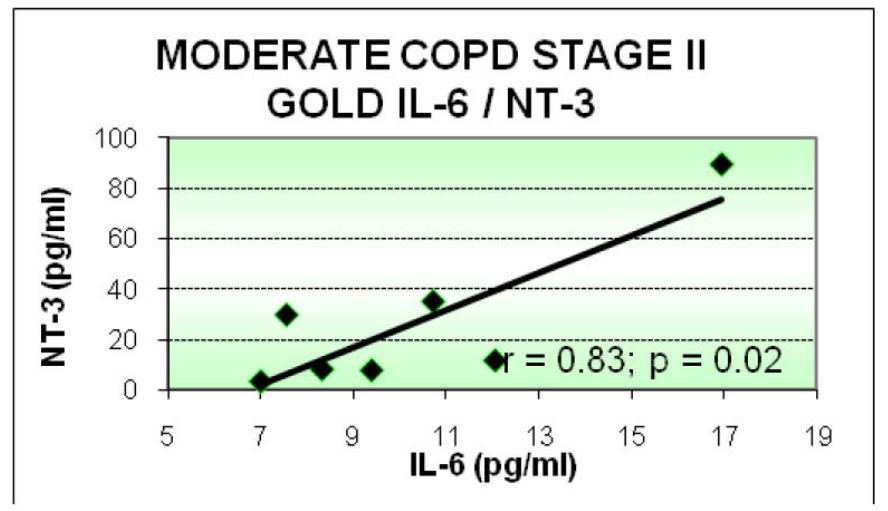

Figure 3: Correlation between serum level of NT-3 and IL-6 in patients with moderate COPD stage II GOLD

Our study suggests that the pro-inflammatory cytokines IL-1 $\beta$, TNF $\alpha$,IL- 6 and NT-3 were secreted in different proportions and with different dynamics. Thus the direct, or the absence of correlation, could be of predictive value, allowing us to consider several hypotheses:

1. NT-3 levels in COPD patients were positively/direct correlated with IL-1 $\beta$, TNF- $\alpha$, IL-6 and this correlation was associated with moderate COPD stage II GOLD. This correlation shows that the chronic airway inflammation was followed by fibrosis, the main process in COPD stage II GOLD. Proinflammatory cytokines and NT-3 have been recognized as mediators of both protective and degenerative mechanisms. In our previous studies we have shown that NT-3 can modulate the production of the pro-inflammatory cytokine IL-6, post TNF- $\alpha$ responses in patients with favourable prognosis in ischemic stroke. But in COPD, NT-3 cannot modulated the production of the proinflammatory cytokines. The direct correlation show the effort made by NT-3 for the limitation of the local inflammation in COPD by peribronchiolar fibrosis. IL-1 $\beta$ induces neurotrophin expression in human bronchial smooth muscle cells. NT-3 stimulates cell migration and lung repair, as evidenced by de novo synthesis and tissue accumulation of elastin and collagen. But this scarring of the lung tissue results in the permanent loss of transporting oxygen to the body. The formation of scar tissue diminishes the ability of the alveolar sacs to function properly. The more scarring of the tissue occurs, the less likely the patient will be able to breath properly. In addition neurons may be targets for NT-3 and that may evoke airway hyperreactivity, a tendency to sudden narrowing of the air passages of the lungs in response to danger signals. If the disease progresses the lung tissues eventually thicken and become stiff, leading to breathlessness and difficulty of breathing.

2. In cases of exacerbated COPD, with greater degrees of obstruction of the airways, higher levels of TNF- $\alpha$ were noticed in serum. The high TNF- $\alpha$ level in serum was detected in patients with severe COPD stage III and IV GOLD. NT-3 expression is transcriptionally downregulated in this situation. Lung fibrosis has inhibitory effects on neurotrophin secretion in the airways. The possible 
functional consequence of lower levels of neurotrophins in the airways of COPD patients is the absence of correlation between NT-3 and the proinflammatory cytokines that we studied in patients with severe and very severe GOLD stage III, IV GOLD. Long-term exposure to TNF- $\alpha$, IL-6, IL-1 $\beta$ associated with the low level of NT-3, induce high ICAM-1 expression on endothelial cells, mucouscell metaplasia and increase the reactivity of the airway smooth-muscle cells, leading to severe COPD.

Dynamics of innate immunity cytokines in patients with COPD. We suggest that, depending on the local pro-inflammatory cytokines, NT-3 may have a dual role: pro and anti-apoptotic. For the NT-3 there are described two types of surface receptors: Trk and the p75 neurotrophin receptor $\left(\mathrm{p} 75^{\mathrm{NTR}}\right)$, a member of the TNF receptor superfamily. The cytoplasmatic portion of the $\mathrm{p} 75^{\mathrm{NTR}}$ receptor contains a death domain sequence similar to the intracellular domain of the Fas and TNFR. The presence of TNF- $\alpha$ in chronic inflammation may induced overexpression of $\mathrm{p} 75^{\mathrm{NTR}}$ and can induce apoptosis in cells sensitive to NT-3 Metabolites generated by the local neural stimulation of chronic inflammation in COPD, causes a crash in the neural response by the following mechanisms:

1. Secretion of pro-neurotrophine with a large molecule that binds with high affinity to p $75^{\mathrm{NTR}}$, leading to an enhanced secretion of intracellular ceramide, followed by induction of Fasdependent apoptosis; this effect is increased by secretion of TNF that induces activation of proapoptotic domain (death domain).

2. Mature NT-3 is fixed on Trk receptor and induces activation of phospholipase C (PLC) with an antiapoptotic effect. Mature NT-3 secretion in the early stages of COPD, have antiapoptotic effects, and large molecules, immature, induce cell death, contributing to the destruction of lung parenchyma.

\section{Conclusions}

Our results showed that NT-3 lost its immumomodulatory role on pro-inflammatory cytokines in patients with COPD, suggesting the potential pathophysiological role of NT-3 as a mediator involved in airway inflammation and tissue remodeling in the COPD pathogenesis. Reduced lung function is associated with increased levels of systemic pro-inflammatory cytokines and decreased serum level of NT-3. Depending on the cytokines profile, NT-3 can exhibit or not an endogenous immuno-modulatory activity, aspect that may have important pathophysiological and therapeutic implications in subjects with COPD. These results contribute to a better understanding regarding the involvement of NT-3 in the COPD, and give further support to the concept of neurotrophins as mediators involved in protection of airway in inflammatory processes and tissue remodeling.

\section{References}

[1] Robert P. Schleimer, Innate Immune Responses and COPD, Proc Am Thorac Soc Vol 2. pp 342-346, 2005

[2] Baines K.J, Simpson J.L, Gibson P.G., Innate immune responses are increased in Chronic Obstructive Pulmonary Disease, PLoS ONE 6(3): doi:10.1371/journal.pone.0018426, 2011

[3] Tsoumakidou M., Bouloukaki I., Thimaki K., Tzanakis N., Siafakas NM, Innate immunity proteins in chronic obstructive pulmonary disease and idiopathic pulmonary fibrosis, Exp Lung Res. 36(6):373-8, 2010 
[4] Dagnell C., Kemi C, Klominek J., Eriksson P., Sköld CM., Eklund A., Grunewald J., Olgart Höglund C, Effects of neurotrophins on human bronchial smooth muscle cell migration and matrix metalloproteinase-9 secretion, Transl Res.; 150(5):303-10, 2007

[5] Tucker K. L., Meyer, M., Barde, Y. A., Neurotrophins are required for nerve growth during development, Nat Neurosci, 4(1), 29-37, 2001.

[6] Ricci A., Felici L., Mariotta S., Mannino F., Schmid G., Terzano C., Cardillo G., Amenta F. and Bronzetti E., Neurotrophin and Neurotrophin Receptor Protein Expression in the Human Lung, American Journal of Respiratory Cell and Molecular Biology. Vol. 30, pp. 12-19, 2004

[7] Green R.M., Gally F., Keeney J.G., Alper S., Gao B., Han M., Martin R.J., Weinberger A.R., Case S.R., Minor M.N., Chu H.W., Impact of cigarette smoke exposure on innate immunity: a Caenorhabditis elegans model, PLoS One. 31;4(8), 2009

[8] Jeffrey C.L., Freeman C., Hogg J.C., Proceedings of the American Thoracic Society ;4(7):512-21, 2007

[9] Hasday J. D., Bascom R., Joseph J., Fitzgerald T., B.S , Dubin W., Bacterial Endotoxin is an active component of cigarette smoke, CHEST vol. 115 no. 3 829-835, 1999

[10] Rylander, R., Bake, B., Fischer, J.J., et al Pulmonary function and symptoms after inhalation of endotoxins, Am Rev Respir Dis;140,981-986, 1989

[11] Tsoumakidou, M., Tsiligianni, I., Tzanakis N., Mechanisms of altered cell limunity and cytotoxicity in COPD, Current Drug Targets, Volume 12, Number 4, pp. 450-459(10), 2011

[12] Akira S., Toll-like receptors and innate immunity, Adv Immunol; 78:1-56, 2001

[13] Zuany-Amorim C., Hastewell J., Walker C.,Toll-like receptors as potential therapeutic targets for multiple diseases, Nature Reviews Drug Discovery 1, 797-807, 2002

[14] Bachar O., Adner M., and Cardell L.O.,Toll-like receptor activation in airway smooth muscle: dual actions via separate MAPK pathways, AJP - Lung Physiol vol. 291 no. 3, 2006

[15] Droemann D., Goldmann T., Tiedje T., Zabel P., Dalhoff K., Schaaf B., Toll-like receptor 2 expression is decreased on alveolar macrophages in cigarette smokers and COPD patients, Respir Res. $8 ; 6: 68,2005$

[16] Mortaz E., Adcock I.M., Ito K., Kraneveld A.D, Nijkamp F.P., Folkerts G., Cigarette smoke induces CXCL8 production by human neutrophils via activation of TLR9 receptor, ERJ November 1, vol. 36 no. 5 1143-1154, 2010

[17] Pons J., Sauleda J., Regueiro V., Santos C., López M., Ferrer J., Agustí A.G.N and Bengoechea J.A., Expression of Toll-like receptor 2 is up-regulated in monocytes from patients with chronic obstructive pulmonary disease, Respiratory Research Volume 7, Number 1, 64, 2006

[18] Akbari O., Stock P., Meyer E., Kronenberg M., Sidobre S., Nakayama T., Taniguchi M., Grusby M.J., DeKruyff R.H., Umetsu DT., Essential role of NKT cells producing IL-4 and IL-13 in the development of allergen-induced airway hyperreactivity, Nat Med. 9(5):582-8, 2003

[19] Urbanowicz R.A., Lamb J.R., Todd I., Corne J.M., Fairclough L.C., Enhanced effector function of cytotoxic cells in the induced sputum of COPD patients, Respir Res. 11;11:76, 2010

[20] Laird-Michelle H. W; Rhee S.H., Perkins D. J., Medvedev A., Piao W., Fenton M. J., Vogel S.,TLR4/MyD88/PI3K interactions regulate TLR4 signaling, Journal of leukocyte biology;85(6):966-77, 2009

[21] Chung K.F., Cytokines in chronic obstructive pulmonary disease, ERJ July 2, vol. 18 no. 34 suppl $50 s-59 s, 2001$

[22] Wouters E.F., Reynaert N.L., Dentener M.A., Vernooy J.H., Systemic and local inflammation in asthma and chronic obstructive pulmonary disease: is there a connection? Proc Am Thorac Soc.;6(8):638-47, 2009

[23] Yanbaeva D.G., Dentener M.A., Spruit M.A., Houwing-Duistermaat J.J., Kotz D., Passos V.L., Wouters E.F., IL6 and CRP haplotypes are associated with COPD risk and systemic inflammation: a casecontrol study. BMC Med Genet. 9;10:23, 2009

[24] Pons J., Sauleda J., Ferrer J.M., Barceló B., Fuster A., Regueiro V., Julià M.R., Agustí A.G., Blunted gamma delta T-lymphocyte response in chronic obstructive pulmonary disease, Eur Respir J.;25(3):441-6, 2005

[25] Pasarica D., Gheorghiu M., Topârceanu F., Bleotu C., Ichim L., Trandafir T., Neurotrophin-3, TNFalpha and IL-6 relations in serum and cerebrospinal fluid of ischemic stroke patients, Roum Arch Microbiol Immunol.;64(1-4):27-33, 2005.

[26] Kemi C., Grunewald J., Eklund A., Höglund C.O., Differential regulation of neurotrophin expression in human bronchial smooth muscle cells, Respiratory Research, 7:18 doi:10.1186/1465-9921-7-18, 2006 